\title{
Co-magmatic sulfides and sulfates in the Udachnaya-East pipe (Siberia) : sulfur speciation and isotopic composition in kimberlites and their mantle sources
}

\author{
Y. Kitayama ${ }^{1}$, E. Thomassot ${ }^{1}$, A. Galy ${ }^{1}$, A. Golovin ${ }^{2}$, A. Korsakov ${ }^{2}$, Elisabeth d'Eyrames ${ }^{1}$, \\ Nelly Assayag ${ }^{3}$, Nordine Bouden ${ }^{1}$, D. Ionov ${ }^{3}$ \\ ${ }^{1}$ Centre de Recherches Pétrographiques et Géochimiques, Vandoeuvre-les-Nancy, France \\ ${ }^{2}$ Sobolev Institute of Geology and Mineralogy, Novosibirsk, Russia \\ ${ }^{3}$ Institut de Physique du Globe, Paris, France. \\ ${ }^{4}$ Géosciences Montpellier, Montpellier, France
}

\section{Introduction}

Kimberlite magmas travel at high speed through the lithospheric mantle and crust, propelled by their high volatile contents. The origin of volatiles in kimberlite magma, however, is still debated. The loss of volatiles during eruption, the composite nature of kimberlites and their common hydrous alteration make the primary kimberlitic melt composition difficult to infer. Volatiles in the mantle source of kimberlites may come from the recycling of Archean oceanic crust into the lithospheric mantle, as suggested by the finding of Archean ages for eclogite xenoliths from the Udachnaya-East kimberlite (Siberia), thought to represent remnants of early oceanic crust (Pearson et al. 1995; Jacob \& Foley 1999). However, a single Archean formation age for the Siberian lithospheric mantle has been challenged by recent publications (Doucet et al. 2015; Ionov et al. 2015 and Moyen et al. 2017) that propose a major rejuvenation of the Archean lithosphere during the paleoproterozoic (ca $1.9 \mathrm{Ga}$ ). Here we present new insights from multiple S-isotopes $\left({ }^{32} \mathrm{~S},{ }^{34} \mathrm{~S},{ }^{33} \mathrm{~S},{ }^{36} \mathrm{~S}\right.$ ), to test whether a surface-derived Archean component is present in the mantle source of the Udachnaya-East kimberlite. Photolytic reactions in the ozone-free atmosphere of the early Earth, produced mass-independent fractionation of sulfur (corresponding to a deviation from the mass-dependent fractionation line). These anomalies were efficiently transferred to sediments such as Archean sedimentary sulfides that carry positive $\Delta^{33} \mathrm{~S}$ anomalies (and negative $\Delta^{36} \mathrm{~S}$ anomalies) and Archean sulfates that carry negative $\Delta^{33} \mathrm{~S}$ (with positive $\Delta^{36} \mathrm{~S}$ ). Accordingly, the presence of these anomalies in igneous rocks may allow to identify Archean surface material recycled into the mantle. If found in kimberlites samples, mass-independent fractionation of sulfur would indicate unambiguously that recycling of Archean supracrustal material was involved in the source of the Udachnaya-East kimberlite.

\section{Methodology}

Sulfur isotopic values are reported in the notation $\delta$ with respect to V-CDT (Vienna-Canon Diablo Troilite) defined as: $\delta^{3 \mathrm{x}} \mathrm{S}($ in $\%$ o $)=1000 *\left[\left({ }^{3 \mathrm{x}} \mathrm{S} /{ }^{32} \mathrm{~S}\right)_{\text {sample }} /\left({ }^{3 \mathrm{x}} \mathrm{S} /{ }^{32} \mathrm{~S}\right)_{\mathrm{V}-\mathrm{CDT}}-1\right]$,

where ${ }^{3 \mathrm{x}} \mathrm{S}$ corresponds to one of the minor stable $\mathrm{S}$ isotopes ${ }^{33} \mathrm{~S},{ }^{34} \mathrm{~S}$ or ${ }^{36} \mathrm{~S}$. Furthermore, $\Delta^{33} \mathrm{~S}$ and $\Delta^{36} \mathrm{~S}$ are defined as: $\Delta^{3 \mathrm{x}} \mathrm{S}($ in $\%$ o $)=1000 *\left[\left({ }^{3 \mathrm{x}} \mathrm{S} /{ }^{32} \mathrm{~S}\right)_{\text {sample }}-\lambda *\left({ }^{34} \mathrm{~S} /{ }^{\beta 2} \mathrm{~S}\right)_{\text {sample }}\right]$,

where $\lambda$ is a coefficient directly related to the mass differences between ${ }^{3 x} \mathrm{~S},{ }^{34} \mathrm{~S}$ and ${ }^{32} \mathrm{~S}\left(0.515\right.$ for ${ }^{33} \mathrm{~S}$ and 1.89 for $\left.{ }^{36} \mathrm{~S}\right)$.

Sulfur contained in bulk samples was extracted as $\mathrm{Ag}_{2} \mathrm{~S}$ by a wet chemistry procedure described in Kitayama et al. (In Press). The extraction was done sequentially in kimberlite samples: first from sulfides, then from sulfates in the same aliquot of sample. After fluorination of $\mathrm{Ag}_{2} \mathrm{~S}$ to $\mathrm{SF}_{6}$ gas and purification of $\mathrm{SF}_{6}$, bulk isotope ratios were measured using a ThermoFinnigan MAT 253 dual-inlet gas-source mass spectrometer.

We studied samples of salty kimberlite, an associated salt-free kimberlite and a serpentinized kimberlitic breccia (also salt-free) and compared them to other sulfur bearing lithologies in the area (hydrothermal minerals, country-rock sediment and brine).

\section{Results and discussion}

Except for one outlier with very low sulfide concentration, $\Delta^{33} \mathrm{~S}$ and $\Delta^{36} \mathrm{~S}$ signatures of sulfides and sulfates in both salty and non-salty kimberlite samples are undistinguishable within uncertainty (Fig. 1). Homogeneous $\Delta^{33} \mathrm{~S}$ and $\Delta^{36} \mathrm{~S}$ signatures are consistent with isotopic equilibrium and support a cogenetic link between groundmass sulfides and sulfates in the salty kimberlite. 


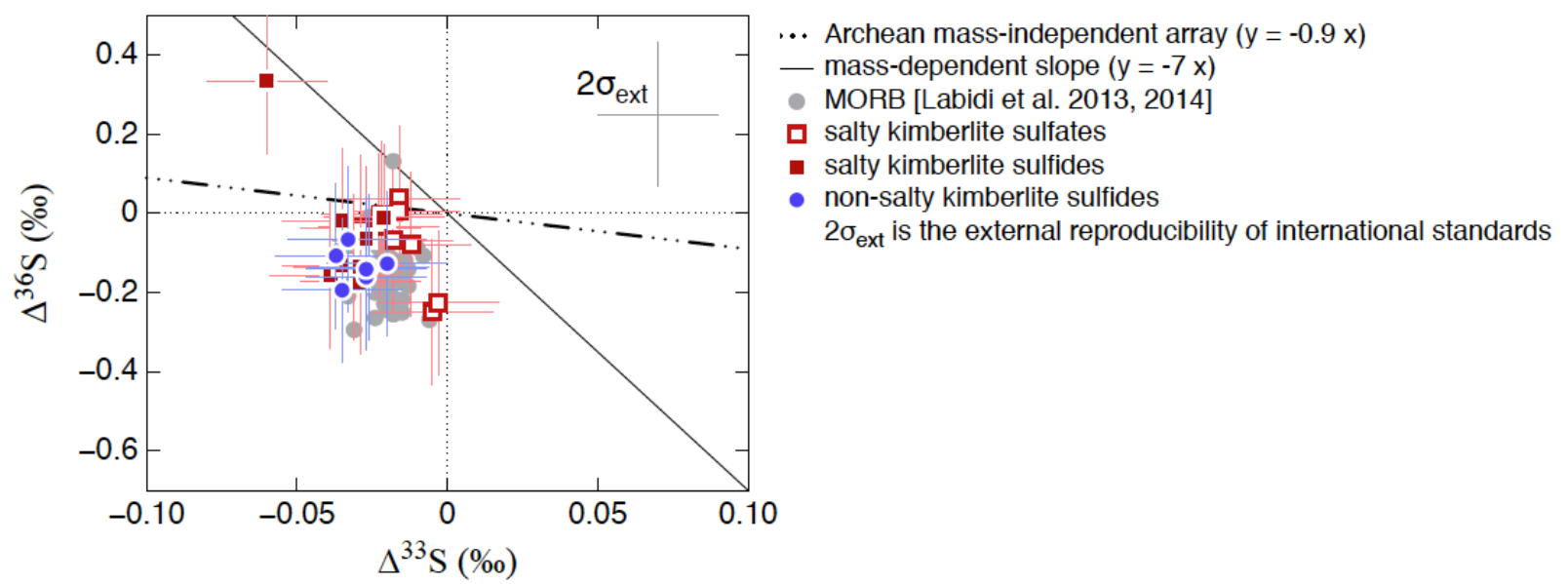

Fig. 1: $\Delta^{36} S$ vs $\Delta^{33} S$ (\%) diagram showing that sulfides and sulfates from salty and non-salty kimberlites are homogeneous and overlap with the range of MORB.

Overall, sulfates and sulfides of the salty and non-salty kimberlites display small but systematically negative signatures in both $\Delta^{33} \mathrm{~S}$ and $\Delta^{36} \mathrm{~S}$ falling in the range of the Canonical mantle value. They are within uncertainty of the V-CDT, and in fact overlap with the compositional range of mid-ocean ridge basalts (MORB) reported by Labidi et al. $(2013,2014)$. They differs from the Archean mass-independent array and the slightly negative $\Delta^{33} \mathrm{~S}$ and $\Delta^{36} \mathrm{~S}$ values are too small to unambiguously determine a contribution from Archean sediments to the source of the Udachnaya-East kimberlite. The data thus show no evidence for mass-independent fractionation and therefore no evidence for the involvement of Archean surface material in the source of the kimberlites. We can infer that either: (1) subducted oceanic crust does not contribute significantly to the source of kimberlite melt; or (2) the subducted oceanic crust in the source does not carry mass-independent fractionation of sulfur or is not Archean in age. The homogeneity of $\Delta^{33} \mathrm{~S}$ and $\Delta^{36} \mathrm{~S}$ in the kimberlite samples suggest that they have not been altered by secondary processes.

There is in fact a larger range of variations in $\Delta^{33} \mathrm{~S}$ and $\Delta^{36} \mathrm{~S}$ when considering hydrothermal sulfur mineralization, country rock sediment or brine samples (Fig. 2). Hydrothermal processes can generate a significant range in $\Delta^{33} \mathrm{~S}$ and $\Delta^{36} \mathrm{~S}$ but spread along a slope characteristic of mass-dependent processes $(\sim-7)$. Furthermore, the brine and country rock sediment are also aligned along a mass-dependent slope. The brine and this sulfate-rich sediment are thus likely related by processes involving Rayleigh fractionation, such as the dissolution or precipitation of sulfate-rich beds.

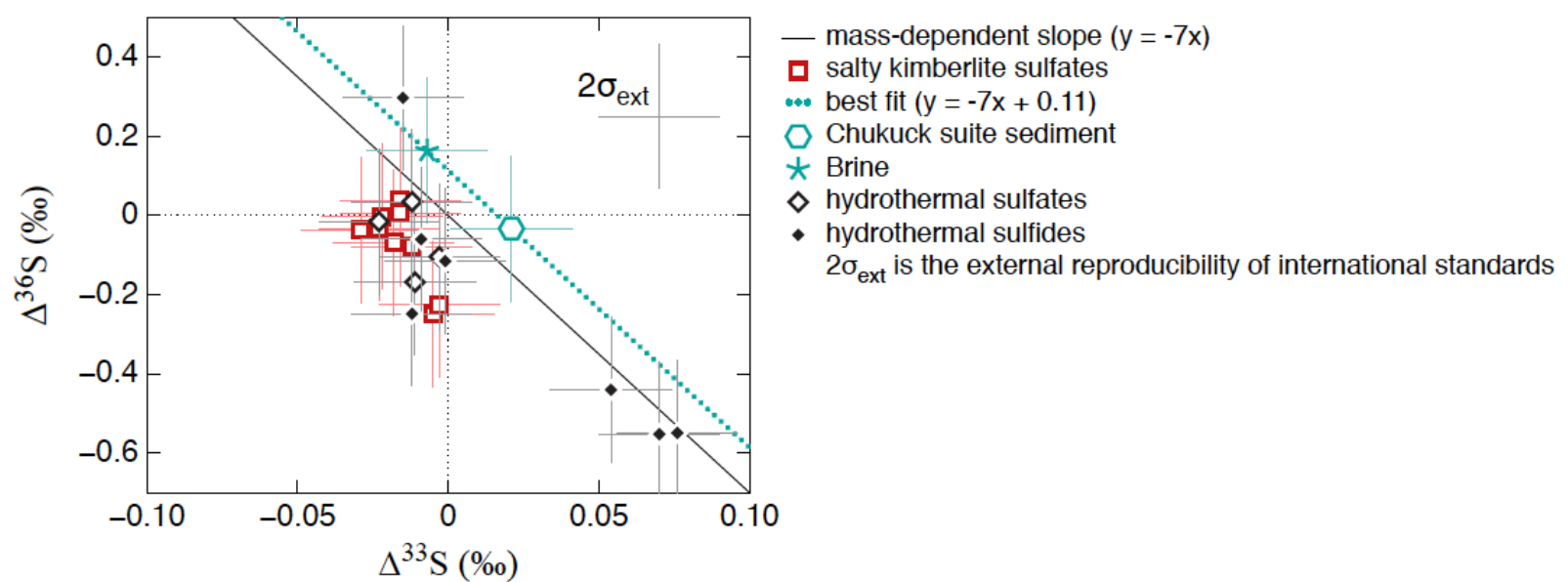

Fig. 2: $\Delta^{36} S$ vs $\Delta^{33} S(\%)$ diagram, comparing the range of salty kimberlite sulfates with that of hydrothermal sulfur, brine and country rock sediments.

It is interesting to note that sulfates of the salty kimberlites define a trend with a slope of $-9 \pm 3(1 \sigma)$, also consistent with mass-dependent processes such as a Rayleigh fractionation but with a y-intercept different from the mass-dependent trend defined by the brine and sulfate-rich sediment (Fig. 3). Thus, the brine and 
the country rock sediment both clearly differ from the salty kimberlite sulfates in terms of their multiple sulfur isotopic compositions.

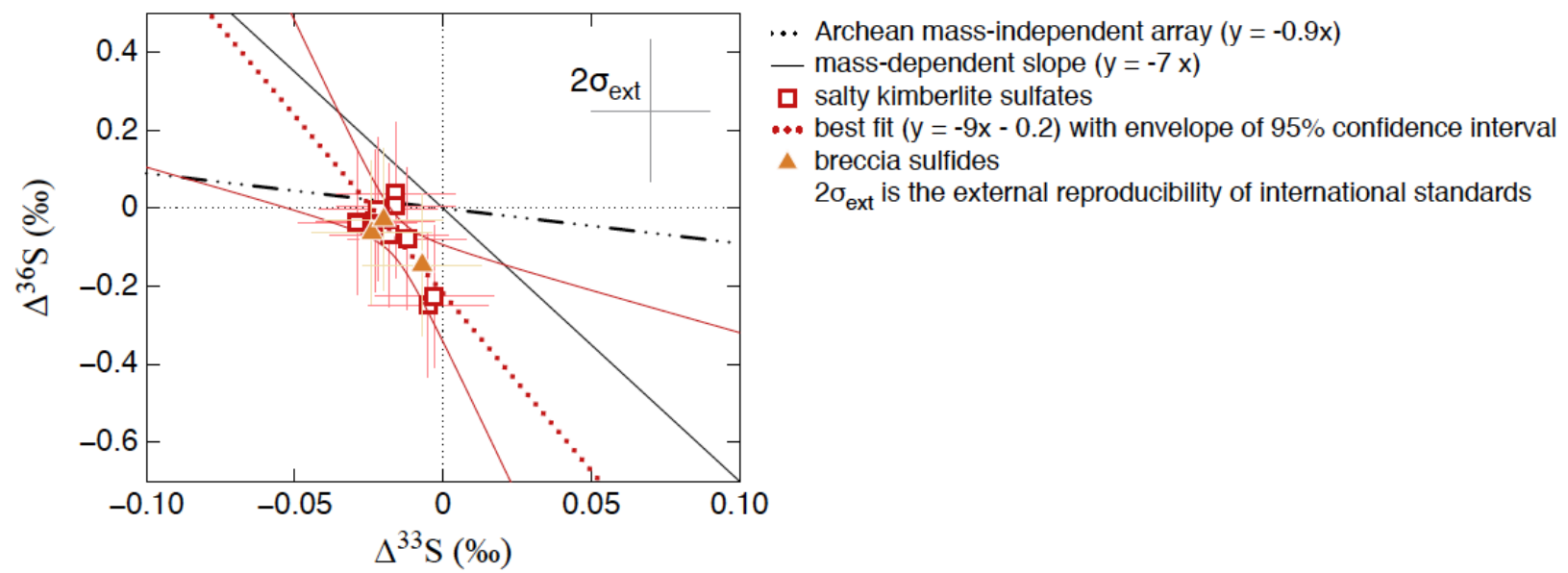

Fig. 3: $\Delta^{36} S$ vs $\Delta^{33} S(\%)$ diagram showing that the salty kimberlite sulfates and the breccia sulfides overlap along a trend consistent with that of mass-dependent processes.

This is consistent with the idea that sulfates from the salty kimberlite are, indeed, of mantle origin and that they may have been partly reduced, resulting in the production of secondary sulfides (Kitayama et al. In Press). The observation that sulfides of the breccia fall along the same trend as the salty kimberlite sulfates also confirms the hypothesis that sulfides from the breccia are derived from the reduction of primary kimberlitic sulfates.

\section{References}

Doucet, L. S., Ionov, D. a., \& Golovin, A. V. (2015). Paleoproterozoic formation age for the Siberian cratonic mantle: $\mathrm{Hf}$ and $\mathrm{Nd}$ isotope data on refractory peridotite xenoliths from the Udachnaya kimberlite. Chemical Geology, 391, 42-55. http://doi.org/10.1016/j.chemgeo.2014.10.018

Dmitri A. Ionov, Richard W. Carlson, Luc S. Doucet, Alexander V. Golovin, O. B. O. (2015). The age and history of the lithospheric mantle of the Siberian craton : Re - Os and PGE study of peridotite xenoliths from the Obnazhennaya kimberlite. Earth and Planetary Science Letters, (August). http://doi.org/10.1016/j.eps1.2015.07.007

Jacob, D. E., \& Foley, S. F. (1999). Evidence for Archean ocean crust with low high field strength element signature from diamondiferous eclogite xenoliths. Developments in Geotectonics, 24(C), 317-336. http://doi.org/10.1016/S0419-0254(99)80017-2

Kitayama, Y., Thomassot, E., Galy, A., Golovin, A., Korsakov, A., D’Eyrames, E., Assayag, N., Bouden, N, \& Ionov, D. (In Press). Co-magmatic sulfides and sulfates in the Udachnaya-East pipe (Siberia ): A record of the redox state and isotopic composition of sulfur in kimberlites and their mantle sources. http://doi.org/10.1016/j.chemgeo.2016.10.037

Labidi, J., Cartigny, P., Hamelin, C., Moreira, M., \& Dosso, L. (2014). Sulfur isotope budget (32S, 33S, 34S and 36S) in Pacific-Antarctic ridge basalts: A record of mantle source heterogeneity and hydrothermal sulfide assimilation. Geochimica et Cosmochimica Acta, 133, 47-67. http://doi.org/10.1016/j.gca.2014.02.023

Labidi, J., Cartigny, P., \& Moreira, M. (2013). Non-chondritic sulphur isotope composition of the terrestrial mantle. Nature, 501(7466), 208-11. http://doi.org/10.1038/nature12490

Moyen, J., Paquette, J., Ionov, D. A., Gannoun, A., Korsakov, A. V, Golovin, A. V, \& Moine, B. N. (2017). Paleoproterozoic rejuvenation and replacement of Archaean lithosphere : Evidence from zircon $\mathrm{U}-\mathrm{Pb}$ dating and $\mathrm{Hf}$ isotopes in crustal xenoliths at Udachnaya, Siberian craton. Earth and Planetary Science Letters, 457, 149-159. http://doi.org/10.1016/j.eps1.2016.09.046

Ono, S., Beukes, N. J., Rumble, D., \& Fogel, M. L. (2006). Early evolution of atmospheric oxygen from multiple-sulfur and carbon isotope records of the 2.9 Ga Mozaan Group of the Pongola Supergroup, Southern Africa. South African Journal of Geology. http://doi.org/10.2113/gssajg.109.1-2.97

Pearson, D. G., Snyder, G. A., Shirey, S. B., Taylor, L. A., Carlson, R. W., \& Sobolev, N. V. (1995). Archaean Re-Os age for Siberian eclogites and constraints on Archaean tectonics. Nature, 374(6524), 711-713. http://doi.org/10.1038/374711a0 